\title{
K3 DALAM KEPERAWATAN di RUMAH SAKIT
}

\author{
Cindy Minannisa
}

\section{cindyminannisa01@gmail.com}

\begin{abstract}
Abstrak
K3 adalah upaya yang bertujuan untuk meningkatkan dan memelihara derajat kesehatan fisik, mental dan sosial yang setinggi-tingginya bagi pekerja di semua jenis pekerjaan, pencegahan terhadap gangguan kesehatan pekerja yang disebabkan oleh kondisi pekerjaan; perlindungan bagi pekerja dalam pekerjaannya dari risiko akibat faktor yang merugikan kesehatan. Keperawatan merupakan suatu bentuk pelayanan profesional bersifat humanistik, menggunakan pendekatan holistik, dilakukan berdasarkan ilmu dan kiat keperawatan, berorientasi kepada kebutuhan objektif klien. Rumah Sakit (RS) termasuk dalam kriteria tempat kerja dengan berbagai ancaman bahaya yang berdampak kepada kesehatan, tidak hanya terhadap para pelaku langsung yang bekerja di RS, tapi juga terhadap pasien maupun pengunjung RS. Sehingga seharusnya pihak pengelola RS menerapkan upaya-upaya K3 di RS. Tujuan: untuk mengetahui bagaimana k3 dalam keperawatan di rumah sakit. Metode: Tugas ini menggunakan metode Literature review dimana dilakukan dengan cara menganalisis kajian dan eksplorasi jurnal, text book, maupun e-book yang relevan dan membahas tentang hal-hal mengenai k3 dalam keperawatan di rumah sakit. Hasil: Hasil dari pengkajian ini dengan menggunakan metode literatur review adalah dengan membaca pengkajian ini pembaca dapat menegetahui tujuan, manfaat dan berapa penting k3 dalam keperawatan di terapkan di rumah sakit.
\end{abstract}

\section{Kata Kunci: K3, Keperawatan, Rumah Sakit}

\section{Latar Belakang}

Keselamatan menjadi isu global dan terangkum dalam lima isu penting yang terkait di rumah sakit yaitu keselamatan pasien, keselamatan pekerja atau petugas kesehatan, keselamatan bangunan dan peralatan di rumah sakit, keselamatan lingkungan dan keselamatan bisnis rumah sakit yang terkait dengan kelangsungan hidup rumah sakit. Mengingat masalah keselamatan pasien merupakan masalah yang perlu ditangani segera maka diperlukan standar keselamatan pasien fasilitas pelayanan kesehatan yang merupakan acuan untuk melaksanakan kegiatannya. 
Berdasarkan Permenkes RI Nomor 11 Tahun 2017 tentang Keselamatan Pasien bahwa setiap fasilitas pelayanan kesehatan harus menyelenggarakan keselamatan pasien.

Keselamatan menjadi isu global dan terangkum dalam lima isu penting yang terkait di rumah sakit yaitu keselamatan pasien, keselamatan pekerja atau petugas kesehatan, keselamatan bangunan dan peralatan di rumah sakit yang bisa berdampak terhadap keselamatan pasien dan petugas. Keselamatan lingkungan yang berdampak terhadap pencemaran lingkungan dan keselamatan bisnis rumah sakit yang terkait dengan kelangsungan hidup rumah sakit. Keselamatan pasien merupakan prioritas utama untuk dilaksanakan terkait dengan isu mutu dan citra perumahsakitan. Gerakan (Patient Safety) keselamatan pasien telah menjadi spirit dalam pelayanan rumah sakit seluruh dunia tidak hanya rumah sakit di negara maju yang menerapkan keselamatan pasien untuk menjamin mutu pelayanan, tetapi juga rumah sakit di negara berkembang seperti di Indonesia (Depkes, 2006).

Standar Kesehatan dan Keselamatan Kerja di RS (K3RS) perlu ditetapkan untuk mencegah dan mengurangi risiko kecelakaan dan penyakit akibat kerja di RS.Demi terciptanya jaminan keselamatan kerja maka diperlukan pelayanan strategis yang profesional serta prosedur kerja yang tetap, tidak hanya tergantung pada peraturan-peraturan yang mengayominya dan finansial yang diberikan, melainkan banyak faktor yang harus ikut terlibat, diantaranya adalah pelaksanaan organisasi.Suatu organisasi yang berhasil dapat diukur dengan melihat pada sejauh mana organisasi tersebut dapat mencapai tujuannya.Pelaksanaan K3 di RS dapat dinilai dari kefektivitasan organisasi K3 tersebut (Kun dwi apriliawati,2017).

Keselamatan pasien merupakan dasar dari pelayanan kesehatan yang baik. Pengetahuan tenaga kesehatan dalam sasaran keselamatan pasien terdiri dari ketepatan identifikasi pasien, peningkatan komunikasi yang efektif, peningkatan keamanan obat yang perlu diwaspadai, kepastian tepat lokasi, prosedur, dan tepat pasien operasi, pengurangan risiko infeksi, pengurangan risiko pasien jatuh.

Keselamatan pasien merupakan dasar dari pelayanan kesehatan yang baik. Pengetahuan tenaga kesehatan dalam sasaran keselamatan pasien terdiri dari ketepatan identifikasi pasien, peningkatan komunikasi yang efektif, peningkatan keamanan obat yang perlu diwaspadai, 
kepastian tepat lokasi, prosedur, dan tepat pasien operasi, pengurangan risiko infeksi, pengurangan risiko pasien jatuh dan insedin lainnya.

\section{Metode}

Metode yang saya gunakan adalah Literature review dimana dilakukan dengan cara menganalisis kajian dan eksplorasi jurnal, text book, maupun e-book yang relevan dan membahas tentang K3 dalam keperawatan di rumah sakit. Dengan metode ini informasi pembahasan mengenai K3 dalam keperawatan di rumah sakit dapat dihami. Sumber yang digunakan bersifat subjektif yaitu proses penulisan yang lebih fokus pada landasan teori. Dan melakukan analisis buku dan e-jurnal yang relevan dan berfokus kepada pengaplikasian berfikir kritis dalam mengelola informasi dan komunikasi keperawatan. Sumber yang digunakan adalah sumber yang diterbitkan di 8 tahun terakhir dan referensi akan dicantumkan dibagian daftar pustaka.

\section{Hasil}

Rumah sakit (RS) merupakan tempat kerja yang berpotensi tinggi terhadap terjadinya kecelakaan kerja. Adanya bahan mudah terbakar, gas medis, radiasi pengion dan bahan kimia membutuhkan perhatian serius terhadap keselamatan pasien, staf dan umum (Sarastuti, 2016).

Perawat sebagai pemberi layanan kesehatan memiliki tanggung jawab yang besar dalam memberi tindakan kepada pasien dimana dengan tujuan agar tercapainya derajat kesehatan. Setiap tindakan yang akan di berikan tentunya memiliki resiko tertentu yang dapat merugikan kklien ataupun perawat itu sendiri. Maka untuk menghindari hal tersebut perawat perlu dibekali ilmu pengetahuan dan pengalaman yang baik dalam pelaksnaan K3 di Rumah Sakit.

Menurut Honda dkk (2014) dalam penelitian di Thailand, terdapat hubungan yang signifikan antara sikap perawat terhadap pencegahan cidera/ kecelakaan akibat benda tajam dan terjadinya cidera akibat benda tajam. Perawat yang memiliki sikap negative terhadap pencegahan cidera benda tajam hampir dua kali cenderung terkena cidera benda tajam dibandingkan dengan yang bersikap positif. Rumah sakit dapat mengurangi jumlah kejadian tertusuk benda tajam dengan meningkatkan sikap perawat dimana sikap sangat berhubungan dengan perilaku. Penelitian ini sesuai juga dengan penelitian yang dilakukan oleh Salawati (2009) dan Sandewa (2014) bahwa sikap ada hubungan dengan kejadian kecelakaan kerja. 
Perawat merupakan petugas kesehatan dengan presentasi terbesar dan memegang peranan penting dalam pemberian pelayanan kesehatan. Dalam menjalankan tugasnya perawat berisiko mengalami gangguan kesehatan dan keselamatan kerja (K3). Perilaku manusia terdiri dari faktor internal dan faktor eksternal. Faktor internal yaitu karakteristik dari individu yang bersangkutan yang bersifat bawaan sedangkan faktor eksternal yaitu faktor yang berasal dari luar diri seseorang (Notoatmodjo, 2010). Berdasarkan hasil penelitian dapat disimpulkan bahwa sebagian besar perawat pelaksana memiliki perilaku yang baik dalam penerapan manajemen Kesehatan dan Keselamatan Kerja (K3) baik ditinjau dari faktor internal (52.5\%) maupun faktor eksternal $(58.8 \%)$.

Sebagai perawat atau karyawan, berhak memperoleh lingkungan kerja yang aman. Beberapa rumah sakit mungkin memperkerjakan perawat untuk memeriksa keamanan lingkungan dan memgunakan praktik kerja untuk menigkatkan keselamatan kerja. Ada beberapa hal tentang keselamatan kerja perawat di rumah sakit : Penyetaraan kerja dalam bagian kesehatan, khususnya ruang lingkup k3 dalam keperawatan di rumah sakit telah menjadi perhatian yang menonjol. Pembagian tenaga kerja atau staff yg tidak memadai menyebabkan terjadinya kelelahan pada perawat yang menyebabkan cenderung terjadi keselaahan yang dapat membahayakan pasien ataupun perawat tersebut. American Nurse Association (ANA) telah melakukan kampanye besar-besaran bertema "Staffing Saves Lives" hal tersebut memberi gambaran kalau penyetaraan tenaga kerja sangat besar hubungannya dengan Kesehatan dan Keselamatan kerja untuk perawat.

K3 merupakan aspek yang penting dalam usaha meningkatkan kesejahteraan karyawan. Apabila tingkat keselamatan kerja tinggi, maka kecelakaan yang menyebabkan sakit, cacat, dan kematian dapat ditekan sekecil mungkin. Kesehatan dan keselamatan kerja merupakan upaya untuk memberikan jaminan keselamatan dan meningkatkan derajat kesehatan para pekerja/ pemberi layanan kesehatan khususnya perawat dengan cara pencegahan kecelakaan dan penyakit akibat kerja, pengendalian bahaya di tempat kerja, promosi kesehatan, pengobatan dan rehabilitasi.

\section{Pembahasan}

\section{- Pentingnya K3 dalam Keperawatan}


Kecelakaan adalah kejadian tidak terduga yang disebabkan oleh tindakan tidak aman dan kondisi tidak aman (Heinrich, 1930). Sebagian besar (85\%) kecelakaan disebabkan oleh faktor manusia dengan tindakan yang tidak aman. Tindakan tidak aman (unsafe action) adalah tindakan yang dapat membahayakan pekerja itu sendiri maupun orang lain yang dapat menyebabkan terjadinya kecelakaan yang dapat disebabkan oleh berbagai hal.

K3 termasuk sebagai salah satu standar pelayanan yang dinilai di dalam akreditasi RS, disamping standar pelayanan lainnya. Kesehatan dan Keselamatan Kerja (K3) merupakan suatu upaya perlindungan kepada tenaga kerja dan orang lain yang memasuki tempat kerja terhadap bahaya dari akibat kecelakaan kerja. Pekerja RS mempunyai risiko lebih tinggi dibanding pekerja industri lain untuk terjadinya Penyakit Akibat Kerja (PAK) dan KAK, sehingga perlu dibuat standar perlindungan bagi pekerja yang ada di RS.4 Untuk mencegah dan mengurangi resiko bahaya tersebut maka perlu ditetapkan standar K3 di RS. Perlunya pelaksanaan K3RS mengenai kebijakan pemerintah tentang RS di Indonesia adalah untuk meningkatkan akses, keterjangkauan, dan kualitas pelayanan kesehatan yang aman diRS. Perencanaan, pelaksanaan, monitoring, dan evaluasi K3 RS serta tindak lanjut, yang merujuk pada SK Menkes No. 432/ Menkes/ SK/ IV/ 2007 tentang Pedoman Manajemen K3 di RS dan OHSAS 18001 tentang Standar Sistem Manajemen K3.

Perawat merupakan petugas kesehatan dengan presentasi terbesar dan memegang peranan penting dalam pemberian pelayanan kesehatan. Dalam menjalankan tugasnya perawat berisiko mengalami gangguan kesehatan dan keselamatan kerja (K3). Perilaku manusia terdiri dari faktor internal dan faktor eksternal. Faktor internal yaitu karakteristik dari individu yang bersangkutan yang bersifat bawaan sedangkan faktor eksternal yaitu faktor yang berasal dari luar diri seseorang (Notoatmodjo, 2010). Berdasarkan hasil penelitian dapat disimpulkan bahwa sebagian besar perawat pelaksana memiliki perilaku yang baik dalam penerapan manajemen Kesehatan dan Keselamatan Kerja (K3) baik ditinjau dari faktor internal (52.5\%) maupun faktor eksternal $(58.8 \%)$.

Kecelakaan kerja adalah kejadian yang tidak terduga dan tidak diharapkan. Kejadian kecelakaan kerja sering terjadi pada tenaga kesehatan khususnya perawat rumah sakit. Oleh karena itu, diperlukan upaya pembinaan pelaksanaan keselamatan dan kesehatan kerja (K3) agar terhidar dari kecelakaan kerja. 
Pelayanan keperawatan yang berkualitas menjadi faktor penentu tingkat kepuasan pasien. Pelayanan keperawatan yang diberikan semakin baik akan meningkatkan kepuasan pasien (Cahyadi \& Mudayana, 2014; Wulandari, 2015). Pelayanan keperawatan sebagai lini terdepan berperan sangat tinggi atas kepuasan yang diterima pasien (Philip, 2014).

K3 merupakan aspek yang penting dalam usaha meningkatkan kesejahteraan karyawan. Apabila tingkat keselamatan kerja tinggi, maka kecelakaan yang menyebabkan sakit, cacat, dan kematian dapat ditekan sekecil mungkin. Kesehatan dan keselamatan kerja merupakan upaya untuk memberikan jaminan keselamatan dan meningkatkan derajat kesehatan para pekerja/ pemberi layanan kesehatan khususnya perawat dengan cara pencegahan kecelakaan dan penyakit akibat kerja, pengendalian bahaya di tempat kerja, promosi kesehatan, pengobatan dan rehabilitasi.

Pelaksanaan Kesehatan dan Keselamatan Kerja (K3) adalah salah satu bentuk upaya untuk menciptakan tempat kerja yang aman, sehat, bebas dari pencemaran lingkungan, sehingga dapat mengurangi dan atau bebas dari kecelakaan kerja dan penyakit akibat kerja yang pada akhirnya dapat meningkatkan efisiensi dan produktivitas kerja.

\section{- Manfaat dan Tujuan K3 dalam Keperawatan}

Ruang lingkup Keselamatan dan Kesehatan Kerja (K3) harus tetap berada di semua lini kegiatan, baik di sektor formal maupun non formal, sebab potensi ancaman bahaya kecelakaan dan kesehatan kerja selalu akan mengancam dimanapun berada.

Rumah sakit merupakan tempat kerja yang memiliki risiko tinggi terhadap keselamatan dan kesehatan sumber daya manusia rumah sakit, pasien, pendamping pasien, pengunjung, maupun lingkungan rumah sakit.

Keselamatan dan kesehatan kerja (K3) merupakan suatu usaha untuj menciptakan perlindungan dan keamanan dari berbagai resiko kecelakaan dan bahaya baik fisik, mental maupun emosional terhadap pekerja, perusahaan, masyarakat dan lingkungan.

Tujuan K3 adalah mencegah, megurangi, bahkan menihilkan resiko penyakit dan kecelakaan akibat kerja (KAK) serta meningkatkan derajat kesehatan para pekerja sehingga produktivitas kerja meningkat.7 Dalam Undang-Undang Republik Indonesia Nomor 36 Tahun 
2009 Tentang Kesehatan, upaya kesehatan kerja ditunjukkan untuk melindungi pekerja agar hidup sehat dan terbebas dari gangguan kesehatan serta pengaruh buruk yang diakibatkan oleh pekerjaan sehingga sudah seharusnya pihak pengelola RS menerapkan upaya-upaya K3 di RS.

Program keselamatan pasien ini memberikan berbagai manfaat bagi rumah sakit antara lain:

a. Adanya kecenderungan "Green Product" produk yang aman di bidang industri lain seperti halnya menjadi persyaratan dalam berbagai proses transaksi, sehingga suatu produk menjadi semakin laris dan dicari masyarakat.

b. Rumah Sakit yang menerapkan keselamatan pasien akan lebih mendominasi pasar jasa bagi Perusahaan-perusahaan dan Asuransi-asuransi dan menggunakan Rumah Sakit tersebut sebagai provider kesehatan karyawan/klien mereka, dan kemudian di ikuti oleh masyarakat untuk mencari Rumah Sakit yang aman.

c. Kegiatan Rumah Sakit akan lebih memukuskan diri dalam kawasan keselamatan pasien.

\section{- Etika Perawat dalam menjalani K3}

Perawat (nurse) berasal dari bahasa latin yaitu kata nutrix yang berarti merawat atau memelihara. Menurut Kusnanto (2003), perawat adalah seseorang (seorang profesional) yang mempunyai kemampuan, tanggung jawab dan kewenangan melaksanakan pelayanan / asuhan keperawatan pada berbagai jenjang pelayanan keperawatan.

Perawat merupakan petugas kesehatan dengan presentasi terbesar dan memegang peranan penting dalam pemberian pelayanan kesehatan. Dalam menjalankan tugasnya perawat berisiko mengalami gangguan kesehatan dan keselamatan kerja (K3).

Dalam literatur keperawatan dikatakan bahwa etika dimunculkan sebagai moralitas, pengakuankewenangan, kepatuhan pada peraturan, etikasosial, loyal pada rekan kerja serta bertanggung jawab dan mempunyai sifat kemanusiaan. Menurut Cooper (1991), dalam Potter dan Perry (1997), etika keperawatan dikaitkan dengan hubungan antar masyarakat dengan karakter serta sikap perawat terhadap orang lain.Etika keperawatan merupakan standar acuan untuk mengatasi segala macam masalah yang dilakukan oleh praktisi keperawatan terhadap para pasien yang tidak mengindahkan dedikasi moral dalam pelaksanaan tugasnya (Amelia, 2013).Etika keperawatan merujuk pada standar etik yang menentukan dan menuntun perawat dalam praktek sehari-hari (Fry, 1994). 
Keselamatan dan kesehatan kerja RS merupakan salah satu upaya untuk meningkatkan mutu pelayanan RS, khususnya dalam hal kesehatan dan keselamatan bagi sumber daya manusia (SDM) RS, pasien, pengunjung/pengantar pasien, dan masyarakat sekitar RS. K3 termasuk sebagai salah satu standar pelayanan yang dinilai di dalam akreditasi RS, disamping standar pelayanan lainnya.

Keberhasilan program Kesehatan dan Keselamatan Kerja (K3) di rumah sakit tidak lepas dari sikap kepatuhan personal baik dari pihak perawat maupun pihak manajemen atas dalam melaksanaan peraturan dan kebijakan peraturan K3 untuk mendukung pencapaian zero accident di rumah sakit. anajemen risiko k3 RS wajib dilaksanakan secara menyeluruh di rumah sakit, karena kegiatan manajemen resiko bertujuan untuk meminimalkan risiko keselamatan dan kesehatan di rumah sakit sehingga tidak menimbulkan efek buruk terhadap keselamatan dan kesehatan SDM Rumah Sakit, pasien, pendamping pasien atau keluarga, dan pengunjung.

Menurut Bloom (1975) dalam Notoatmodjo (2007), pengetahuan merupakan pemberian bukti seseorang dari proses pengingatan atau pengenalan informasi dan ide yang sudah diperoleh sebelumnya. Kebijakan K3 yang dibuat oleh RS dapat digunakan untuk meningkatkan pengetahuan respondenmeskipun dalam hal ini bukan faktor penyebab pengetahuan meningkat. Kebijakan K3 secara tertulis untuk menuangkan kebijakan RS tentang pelaksanaan K3 dalam organisasi.Kebijakan K3 secara tertulis untuk memberikan informasi kepada pekerja RS, yang mengunjungi RS, dan pihak yang bekerja sama dengan RS terkait kebijakan K3 yang berlaku di RS.

Dalam pemberian pelayanan kesehatan yang optimal di rumah sakit diperlukan sumber daya yang berkualitas. Dengan menggunakan sumber daya yang ada diharapkan rumah sakit dapat menghasilkan suatu output yang maksimal berupa jasa untuk meningkatkan mutu pelayanan. Untuk masalah- masalah tersebut haruslah disadari bahwa keberhasilan rumah sakit antara lain disebabkan sumber daya manusia, sehingga sumber daya manusia dipandang sebagai asset rumah sakit, bahkan merupakan investasi rumah sakit, apabila tenaga tersebut merupakan tenaga yang terampil. Keberhasilan pelayanan di rumah sakit tidak terlepas dari berbagai faktor pelayanan keperawatan yang biasa disebut dengan asuhan keperawatan. Seorang perawat dalam melaksanakan manajemen K3 harus memiliki sikap yang sesuai dengan nilai-nilai kesehatan dimana seluruh nilai positif yang ada dalam dirinya menjadi pendorong perilaku sehat dan menjadi upaya dalam meningkatkan kesehatan dan keselamatan selama bekerja. (Riska, 2017) 
Tanggung jawab perawat erat kaitannya dengan tugas-tugas perawat. Tugas perawat secara umum adalah memenuhi kebutuhan dasar serta mengutamakan dan mengoptimalkan keselamatan pasien. Oleh karena itu, asuhan keperawatan sangan menentukan kualitas dari perawat.

Sikap yang bertanggung jawab sesuai dengan etika keperawatan merupakan salah satu bentuk sikap dan perilaku perawat yang bisa menjalankan konsep k3 di rumah sakit. Selain sikap tanggung jawab, perawat juga memiliki sikap yang bijak dalam mengambil keputusan yang didukung oleh pengetahuan yang dimiliki setiap perawat. Oleh sebab itu para perawat dan tenaga medis lainnya berhasil untuk untuk menjalankan manajemen k3 di rumah sakit dengan benar.

\section{Penutup}

Rumah sakit sebagai industri jasa yang mempunyai beragam persoalan tenaga kerja yang rumit dengan berbagai risiko terkena penyakit akibat kerja bahkan kecelakaan akibat kerja sesuai jenis pekerjaannya, sehingga berkewajiban menerapkan upaya Keselamatan dan Kesehatan Kerja Rumah Sakit (K3RS). Keselamatan pasien (patient safety) adalah permasalahan yang sangat penting dalam setiap pelayanan kesehatan sehingga keselamatan merupakan tanggung jawab dari pemberi jasa pelayanan kesehatan terutama pelayanan keperawatan di setiap unit perawatan baik akut maupun kronis harus berfokus pada keselamatan pasien baik dalam tatanan rumah sakit. Penerapan keselamatan pasien ini dapat terlaksana dalam setiap tugas dan tanggung jawab yang akan dilakukan oleh perawat. Perawat dituntut untuk bertanggung jawab dalam setiap tindakannya khususnya selama melaksanakan tugas baik di rumah sakit, puskesmas, panti, klinik atau masyarakat.

Tanggung jawab perawat erat kaitannya dengan tugas tugas perawat. Tugas perawat secara umum adalah memenuhi kebutuhan dasar serta mengutamakan dan mengoptimalkan keselamatan pasien. Perawat sangatlah berperan penting dalam meningkatan kesehatan dan keselamatan kerja di rumah sakit. Keselamatan dan kesehatan kerja adalah kegiatan yang dirancang untuk menjamin keselamatan dan kesehatan di tempat kerja. Perawat berisiko terhadap kecelakaan dan penyakit akibat pekerjaan. Oleh sebab itu perawat sebaiknya terus mengembangkan pengetahuan dan keterampilan di bidang manajemen keperawatan khususnya terkait Kesehatan dan Keselamatan Kerja (K3). 


\section{Daftar Pustaka}

Azza Ivana, B. W. (2014, Januari). Analisa Komitmen Manajemen Rumah Sakit (RS) Terhadap Keselamatan Dan. JURNAL KESEHATAN MASYARAKAT (e-Journal), 2(1), 35-41.

Dian Putri Maharani, A. S. (2017). PENGETAHUAN, SIKAP, KEBIJAKAN K3 DENGAN PENGGUNAAN. Jurnal of Health Education, 10, 33-38.

Ezra Zimri Ruben Abiam Mantiri, O. R. (2020, Juli). FAKTOR PSIKOLOGI DAN PERILAKU DENGAN PENERAPAN MANAJEMEN KESELAMATAN DAN KESEHATAN KERJA RUMAH SAKIT. Indonesian Journal of Public Health and Community Medicine, 1(3), 19-27.

Hana Ike Dameria Purba, V. I. (2018). STUDI KEBIJAKAN, PERENCANAAN DAN PELAKSANAAN KESELAMATAN DAN KESEHATAN KERJA RUMAH SAKIT (K3RS) DI RUMAH SAKIT UMUM (RSU) MITRA SEJATI MEDAN TAHUN 2018. Jurnal Mutiara Kesehatan Masyarakat, 3(2), 113-124.

Iwan M. Ramdan, A. R. (2017, Desember). Analisis Risiko Kesehatan dan Keselamatan Kerja (K3) pada Perawat. JKP, 5(3), 229-241.

Nanda Hani Juniarti, A. A. (2018). PENERAPAN STANDAR KESELAMATAN PASIEN DI RUMAH SAKIT UMUM DAERAH PROVINSI NUSA TENGGARA BARAT. Jurnal Kesehatan Poltekkes Ternate, 11(2), 93-108.

Putri Wulandini. S, T. K. (2016, Oktober). FAKTOR-FAKTOR YANG BERHUBUNGAN DENGAN PENDOKUMENTASIAN ASUHAN KEPERAWATAN DI RUMAH SAKIT JIWA. NERS JURNAL KEPERAWATAN, 12(2), 131-142.

Riska Nazirah, Y. (2017). PERILAKU PERAWAT DALAM PENERAPAN MANAJEMEN KESEHATAN DAN KESELAMATAN KERJA (K3) DI ACEH. Idea Nursing Journal, $8(3)$.

Sentya Putri, S. E. (2018, Juni). PELAKSANAAN KESELAMATAN DAN KESEHATAN KERJA TERHADAP KEJADIAN KECELAKAAN KERJA PERAWAT RUMAH SAKIT. Jurnal Endurance, 3(2), 271-277. 
Silvia Maria P I, J. W. (2015). KEJADIAN KECELAKAAN KERJA PERAWAT BERDASARKAN TINDAKAN TIDAK AMAN. Jurnal Care, 3(2), 9-17.

Simamora, R. H. (2018). Buku ajar keselamatan pasien melalui timbang terima pasien berbasis komunikasi efektif: SBAR. Medan: USUpress.

Simamora, R. H. (2019). Buku ajar pelaksanaan identifikasi pasien. Uwais Inspirasi Indonesia.

Soputan, G. E. (2019). MANAJEMEN RISIKO KESEHATAN DAN KESELAMATAN KERJA (K3) (Study Kasus Pada Pembangunan Gedung SMA Eben Haezar). Jurnal Ilmiah Media Engineering, 4(4), 229-238.

Tukatman, S. P. (2015, Oktober). ANALISIS KESELAMATAN DAN KESEHATAN KERJA PERAWAT DALAM PENANGANAN PASIEN DI RUMAH SAKIT BENYAMIN GULUH KABUPATEN KOLAKA. Jurnal Ners, 10(2), 343-347. 